\title{
PRODUCTION PLANNING AND CONTROL COMPLEMENTARITY ARCHITECTURE IN SELECTED MANUFACTURING FIRMS IN PORT HARCOURT, NIGERIA
}

\author{
Chris Sam Biriowu, \\ John E. Chikwe ${ }^{2 \mathrm{i}}$ \\ ${ }^{1} \mathrm{PhD}$, Department of Management, \\ Rivers State University, \\ Nigeria \\ 2PhD, Department of Management, \\ University of Port Harcourt, \\ Port Harcourt, Nigeria
}

\begin{abstract}
:
The strategic objective of this study is to empirically have an objective grasp of production planning and control complementarity architecture of five selected manufacturing firms and relevant areas of cost control. The paper empirically explores some facets of production planning and processing analysis in different machines and periods; production divisions and types, scheduling and sequencing of production planning. Capacity planning levels including potential capacity, immediate capacity and effective capacity were strategically discussed. Aspects of production control architecture such as dispatching and functions of the dispatcher were also evaluated. Other related areas of production control examined include: expediting (follow-up) and progressing, and the activities in these production and control elements were objectively handled. The study arrived at the fact that, production planning and control functions complement each other in their functionality. Effective scheduling and sequencing are revealed to be a panacea that help the handling of time, space constraints and associated cost elements in production operations management. It is therefore recommended that, production and control operations functions should complement, and be jealously guided in manufacturing operations.
\end{abstract}

Keywords: production planning; control complementarily architecture; strategic management; manufacturing firms; Port Harcourt

i Correspondence: email sbiriowu@yahoo.com, johnchikwe3@gmail.com 


\section{Introduction}

Planning itself is a decision - making process since it involves selecting from among alternatives. Planning is the process of setting objectives and deciding how they are to be achieved. Planning indicates for each individual what is the expected contribution of his own work and that of his fellows to the life of the organization. Thus, plans are end product of planning process and are special types of decisions, methods that are made in advance of, and in anticipation of some occurrence. The basic plan is a statement of a firm's objective. Planning is strategic in production of goods and services and control complementarity research. Just as decision can be either programmed or nonprogrammed, plans to differ to the extent to which they can be detailed in advance. Part of the reason is that some environments are changing rapidly that forecasting has become probably unreliable. In such situations, specific goals, objectives and standing plans such as policies, procedures and rules are probably not of much use. Instead, planners might identify more general domain and direction for organization, and of an organic structure to ensure the fulfilling of organizational requirements.

Production planning according to Clarke (1989) is defined as, "the means by which a manufacturing plan is determined, information issued for its execution, and data collected and recorded which will enable the plan to be controlled through all its stages". The objectives of production planning include:

- To relate sales requirements to the available production capacity on a time basis, thus ensuring that goods are produced when they are required.

- To ensure that goods are produced in the quantities required and of the correct quality.

- To ensure that production costs are minimized.

Sales forecasts are strategic decisions that constitute the base of firm's production planning. On the basis of up-to-date and accurate sales record, we can forecast the sales potential of the organization for the ensuring three or six months or even for the next year. Production planning translates the sales forecast into master production schedules, prepares estimates of materials, personnel, equipment and required inventory levels.

\subsection{Research Problem and Specific Objectives of the Study}

There is an overwhelming strategic influence of production planning and control in production and operations management, and this has challenged the efficient and effective performance of production-related organizations in our economy. There is also the paucity of knowledge relating to investment decisions criteria (Chikwe and Omojefe, 2017), production and control functions, patterns, types as well as appropriate scheduling and sequencing of manufacturing operations. In specific, the problem and objectives of this study is to critically and empirically examine the strategic influence of production planning and control complementarity processes in strategic management architecture of selected manufacturing firms in Port Harcourt, Nigeria. 


\section{Review of Relevant Literature}

\subsection{Functions of Production Planning}

The functions of production planning (Chikwe and Biriowu, 2018) among others include:

- Preparation of a production forecast in conjunction with the heads of marketing and finance,

- Compilation of master production schedules at budgets,

- Setting up procurement schedules or budgets,

- Determination of personnel requirements and strategic applications of ergonomics (human factor engineering) for the manufacture of products,

- Establishing stockroom procedure,

- Providing inventory control.

\subsection{Divisions of Production Planning}

Production planning according to Clarke (1989), and Urieto, Umoh and Chikwe (2011) consists of three basic divisions (a) production programming (b) routing (c) scheduling and sequencing.

\subsubsection{Production Programming}

Production programming as relatedly opined by Clark (1989) seeks to provide the answer to the question, what is to be done? The solution of this question is the sales forecast obtained from the marketing unit. This serves as the maximum limit of production, what if exceeded, is likely to result in goods being manufactured, but not sold. The production programme relates the sales forecast for a stated period of time to production capacity. If potential sales are expected to exceed production capacity, then it may be possible to increase production capacity; if not then, the marketing department should be informed so that they can take necessary action. For example, in event, one should inform potential customers of possible delays in supply. It is important to note that once production capacity and potential sales are agreed, the detailed short-form production programme should be prepared covering:

- the product to be produced including all detailed variations e.g. colour specification and size,

- the quantities of each product to be produced,

- planned stock levels.

\subsubsection{Routing}

Routing seeks to answer the question, "who is to produce goods and how?" It looks at the manufactured items throughout the production process with the strategic objective of determining the most economic and efficient path. Once the alternative ways have been established, they are examined and the best way adopted. This then becomes the route the production process should follow through the factory. For instance, the sequence of operations to be carried out and departments each product must pass through. 
Selecting the best route will require obtaining the following:

- the product specification which may be obtained from the customer in a job production situation or otherwise from the firm's specialist departments. For example, the design and Research and Development (R\&D) offices,

- the procedure specification, which shows the planned sequence of operations included in the product design.

\subsubsection{Sequencing}

Sequencing is also a division of production planning and an aspect of operations research. In this perspective, our research is concerned with a situation where the effectiveness measures of the variables is a function of the order or sequence in which a series of tasks are performed, as relatedly opined by Clarke (1989) in the following problems:

1) The sequence of jobs assigned to one machine,

2) The sequence of two or more jobs to be processed on two machines,

The above probable scenarios could be considered in cases 1 and 2 examples depicted herein below.

\subsection{Types of Production Planning}

- Project Planning: Here we have a unit type of production under project planning. In this case, a product is produced only once. For instance, a special purpose equipment or machine is to be produced, and we are given basic manufacturing data. On this therefore, we can build up a plan of project production.

- Batch Production Planning: This covers the planning of some special customers or stock orders for lots of parts. For example, batches of components or for lots of product, such as chemicals or textiles. The sales forecast is the basis for production planning when production is in anticipation of demand. Master production schedule or plan or budget is prepared on the basis of sales forecast.

- Continuous (for Mass Production) Planning: This is used on items to be produced on a large scale for the market on the basis of sales forecast. Manufacturing space is allotted to job orders for mass production. Equipment for the job is put into place, the order is carried out, and machines are then re-arranged for the next order. Large orders are also arranged to be executed as to ensure that such a plan and delivery dates are duely met.

- Process or Flow Production: This is as obtainable in oil refinery or in paint manufacturing.

\subsection{Steps in the Production Planning (Chikwe, n.d.)}

- A target figure for profit and/or volume for the forthcoming year is received from the board. 
- The marketing department, using information on such matters as past sales, knowledge of present trends and market research information will set up a tentative forecast, which is submitted to the production and finance departments.

- The production department will consider the feasibility of meeting the tentative forecast, having regard to the production facilities available and obtainable. As a result of this scrutiny, it might be found that one or more sections of the work is overloaded, whereas others are underloaded. Modification for the draft forecast will then be suggested....

- The finance departments will then examine the amended forecast to see if it will satisfactorily meet the company's policy on earnings and investment. This might reveal for example that, the most readily sold product has the lowest profit margin and that the marketing department by requiring a substantial increase in the sales of this product, has seriously affected the total profit yield. From considerations of this kind, the finance department may produce further modification to the forecast.

- With the comments of the production and finance department available, the marketing department will produce another sales forecast which is again scrutinized. However, and eventually, after a series of trials, a forecast is produced which is acceptable to all concerned.

- The final sales forecast is then submitted to the board to be approved or rejected.

- When the sales forecast has been approved by the board, the forecast is translated into master production programme, schedules, and budgets by the production executive and his assistance.

- From the master production programme, estimates of materials, personnel, and equipment required to achieve the objective are prepared. Similarly, desirable levels of all inventories (raw materials, work-in-process of production and finished goods) are estimated to optimize investment in industries.

\subsection{Capacity Planning}

Real or effective capacity is dependent upon what is to be produced. Capacity is a relative term which may be defined as the amount of resources input available relative to output requirements at a particular time. Capacity planning according to Chikwe (2018) may be viewed in three duration:

1) Long range (greater than one year),

2) Intermediate range (monthly or quarterly plans for the next 16 to 18 months), and

3) Short range (less than a month).

The objective of capacity planning as suggested by Chikwe (n.d.) is to match the level of operation to the level of demand (which is uncertain). Therefore, there must be always, that mutual co-operation and coordination between capacity planning done by the production control unit and the demand forecast made by the marketing function.

Capacity planning must take into consideration the load on each machine. The load is the work assigned to a machine or an operator; capacity is the volume of output 
capable of being produced in a convenient period of time. When the load is equal to the capacity, then the department or machine or operator is said to be fully loaded. If the load is greater than the capacity, then the plant is over loaded, while if the load is less than the capacity, the plant is underloaded. The figure below shows the schematic representation of the description.

Figure 1: Load and Capacity Planning

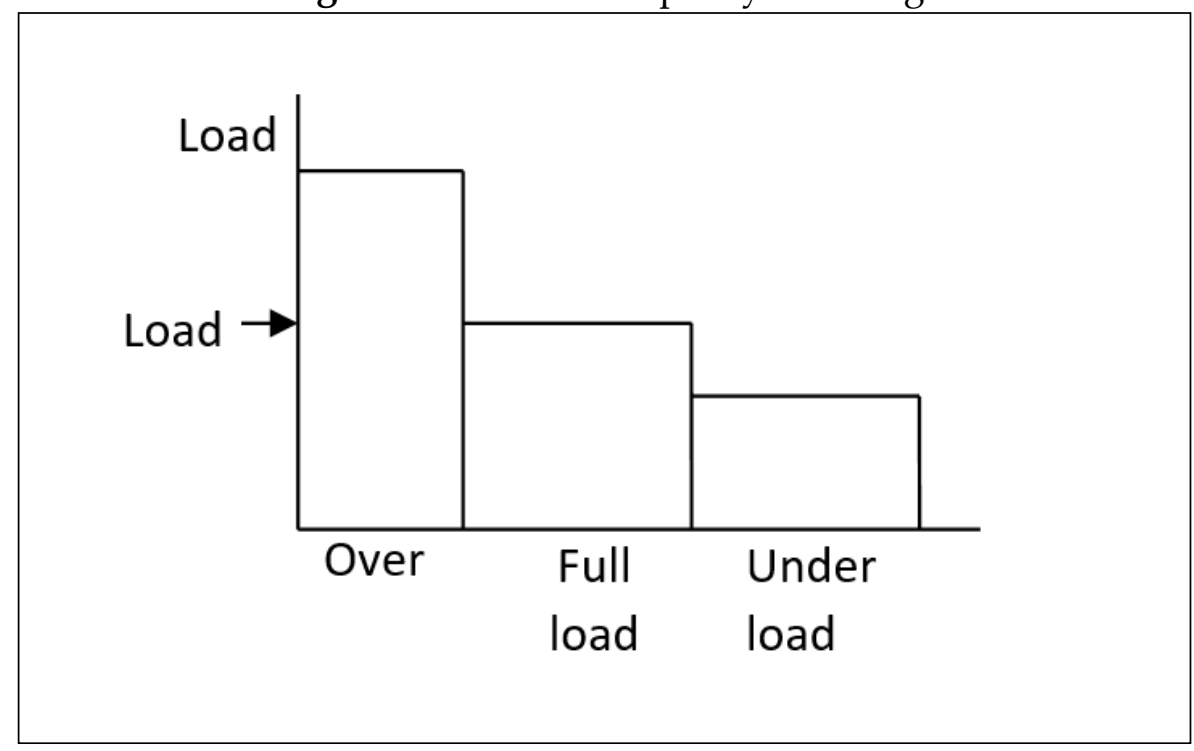

Basically, it is only possible to express a load in hours of work, but it is frequently convenient to express it in other physical terms. For example:

- Money (a machine has an output of Nx an hour).

- Weight (a machine has an output of $x$ kilograms an hour).

- Quantity (a machine has an output of x parts an hour).

In fact, all however, are only sensible if they are expressions of standard hours of work at a known rate of working. The load on a machine/operator will thus lay down the output and time for the period under consideration, and might well take the form of how a machine/operator will operate machine ' $X$ '.

- Monday 8.00am - 5.00pm, operation 1 Job 001

- Tuesday 8.00am - 12.30pm, operation 2 Job 002; 12.30pm - 5.15pm, operation 2 Job 003

- Wednesday 8.00am - 10.30am, operation 1 Job 003; 10.30am - 12.30pm, operation 2 Job 005 and so on.

\subsection{Capacity Levels}

It is also very important for a manager or strategist to know and understand the capacity levels and types of capacity. There are mainly three capacity levels.

1) Potential capacity,

2) Immediate capacity,

3) Effective capacity. 
Potential capacity is that which can be made available within the decision horizon of the most senior executives. Immediate capacity is that which can be made available within the current budget period. Immediate capacity is constrained by:

- Plant size,

- Availability of equipment, labour and cash,

- Financial policies,

- Purchasing and sub-contracting policies,

- Technical demand of the tasks,

- Number of different tasks being carried out.

Effective capacity is that which is used in the current budget period, and can be influenced by:

- Technical abilities in the pre-production stages,

- Organizational skills in the scheduling/loading stages,

- Purchasing skills,

- Sub-contracting skills,

- Maintenance policies and abilities,

- Versatility of labour,

- Efficiency of labour.

\subsection{Production Control}

Production planning and control are like the two sides of a coin and as such, there is every need for the two related and important management concepts to be considered side by side. Control can be defined as the regulation of work activities in accordance or concomitant with predetermined plans so as to ensure the accomplishment of organizational objectives. It could also be defined as the monitoring and modification of organizational activities and resource utilization to ensure the achievement of predetermined standards. Production control is the function of directing and regulating the orderly movement of goods throughout the entire production cycle, from requisitioning of raw materials to the delivery of finished products, to meet the objectives of:

1) Customer service,

2) Minimum inventory investment, and

3) Maximum production efficiency.

In this sense therefore, production control includes production planning as well as production control proper, and inventory control. Production planning covers setting the requirements of production. Production control covers keeping production within the planning requirements.

The main objectives of production control are to ensure that:

- Delivery dates are met,

- Materials and components are available when and where they are required.

- Production capacity (workers, plant and equipment) is neither underutilized nor over-loaded. 


\subsection{Divisions of Production Control}

Production control can be subdivided into four important subdivisions; dispatching, progressing and expediting (follow ups) and ergonomics which is relatively a recent concept in production and operations management.

\subsubsection{Dispatching}

The production orders are issued to the factory or department authorizing and instructing them to make the products called for in the orders. The physical operation of handling a manufacturing order to a machine operator is known as dispatching because the order is dispatched to him. It is the action element of production control. It includes the assignment of work to the machine operators at their machines or work places. Thus, dispatching determines by whom the assigned work will be done. Dispatcher puts the production programme into action as soon as the planning office forwards the manufacturing orders, routs sheets, materials, tools and equipment requisition to the plant. The dispatcher gives the green signal for action when he hands over a work ticket to the machine operator.

\subsubsection{Functions of Dispatcher}

The activities involved in the functioning of the dispatcher include:

- Work assignments to machines, or work places,

- Issue of an order to prepare and perform the job,

- Issue of authority to get necessary tools, materials, fixtures, etc.,

- Guiding and controlling the progress of materials at each operation and making adjustments to schedules and work assignments as conditions demand,

- Authorizing the movement of work from one operation to the next operation,

- Recording and reporting actual output results.

It is important to note that, as the dispatcher operates in the work areas, he is an important person in production control system. In effect therefore, he is the eye and ear of the production control department. He knows both machines and operations, and their plus and minus points. His allocation and reallocation of order ultimately determine the success or failure of manufacturing schedules or programmes.

\subsubsection{Expediting (Follow-up)}

Expediting and inventory control are the controlling agents for controlling the operations of a production system. Follow-up or expediting is the real control feature of production control. Following up the issue of production orders and other directions to ensure that operations are carried on as planned, is the real check for all manufacturing plans. It is through the expediting function that deviations and discrepancies are discovered and prompt appropriate actions are taken to rectify them. Remedial action assures the attainment of goals and objectives. 


\subsubsection{Progressing}

Progressing is a modern term or concept covering all control operations, such as expediting or follow-up of manufacturing process, measuring, comparing and evaluating the actual output in relation to standard output and feedback or reporting deviations, if any, for rectification. The expeditor may also be empowered to take timely decisions and actions to eliminate deviations from planned output. The discrepancies need prompt regulation, control and adjustment. Remedial action on the spot assures accomplishment of goals and objectives. On the whole, production control means work your plan and achieve your targets.

\subsubsection{Ergonomics (Human Factor Engineering)}

This simply means the measurement of work. As argued by Jain and Raw (2009), it deals with the physical and behavioural interaction between the operator, his tools and general environment, with the aim of efficient and economic use of human muscular power. It is also related to the application of work physiology. Ergonomics also relates or endeavours to apply relevant information about human characteristics and behaviors to the design of things people use, the methods by which they are used, and the environment in which people work and live. This human factor engineering is applied in two major areas: the physical devices that people use in performing work and environment in which work is performed. Ergonomics is also the concept used to describe the study of physical management of the work space together with tools used to perform a task. In the application of ergonomics, we try to fit the work to the body rather than forcing the body to conform to the work.

\section{Methodology}

The study adopted the following proven scheduling and sequencing methods and literature in relevant areas and applied same in five selected manufacturing organizations in Port Harcourt, Nigeria. The methods include, shortest processing time rule, minimum slack period rule, mean flow time and mean lateness rule, critical ratio rule, of Clarke (1989), and Johnson's (1954) rule.

\subsection{Data Analysis, Results and Findings}

\section{Case 1: The sequence of jobs processed on one machine}

When $\mathrm{n}$ jobs in the firms are processed through one machine, the shortest processing time rule according to Clarke (1989) will always minimize mean flow and mean lateness. It is important to note that flow time is the time the job spends in the shop. On the other hand, lateness is the amount of time by which the job completion is delayed beyond its due date.

For instance, the following table gives the processing times and due dates for 5 jobs which were processed on a machine. 
PRODUCTION PLANNING AND CONTROL COMPLEMENTARITY ARCHITECTURE

IN SELECTED MANUFACTURING FIRMS IN PORT HARCOURT, NIGERIA

\begin{tabular}{|c|c|c|}
\hline \hline Job & Due Date & Processing Time in days \\
\hline A & 12 days hence & 6 \\
\hline B & 14 days hence & 8 \\
\hline C & 8 days hence & 14 \\
\hline D & 18 days hence & 4 \\
\hline E & 10 days hence & 6 \\
\hline
\end{tabular}

\subsection{Requirements}

a) Assigning of the jobs according to the shortest processing time and calculate mean flow time and mean lateness.

b) Assigning of the jobs according to minimum slack time and calculate the mean flow time and mean lateness.

c) Assigning of the jobs according to minimum critical ratio and calculate the mean flow time and mean lateness.

d) Calculation of which sequence should be used if the objective is to minimize mean flow time and mean lateness.

\subsection{Solution}

a. By the shortest processing time rule according to Clarke (1989), the jobs were assigned in the respective firms in the following order: E, B, C, A, D. The flow time is as hereunder calculated.

\begin{tabular}{|l|c|c|c|c|c|}
\hline Job & E & B & C & A & D \\
\hline Job time in days & 4 & 6 & 8 & 10 & 14 \\
\hline Cumulative time in days & 4 & 10 & 18 & 28 & 42 \\
\hline
\end{tabular}

Relatedly, the mean flow time and mean lateness were calculated as follows:

\begin{tabular}{|c|c|c|c|}
\hline Job & Flow time & Time until due date & Lateness (flow time-time available) \\
\hline A & 28 & 12 & $16(28-12)$ \\
\hline B & 10 & 14 & 0 (No lateness i.e. $10-14=-4)$ \\
\hline C & 18 & 8 & $10(18-8)$ \\
\hline D & 42 & 18 & $24(42-18)$ \\
\hline E & 4 & 10 & $0(4-10)$ \\
\hline & 102 & & 50 \\
\hline
\end{tabular}

Mean flow time $=\frac{102}{5}$ or 20.4 days

Mean lateness $=\frac{50}{5}$ or 10 days

b. The first in this respect is to calculate slack time 
PRODUCTION PLANNING AND CONTROL COMPLEMENTARITY ARCHITECTURE

IN SELECTED MANUFACTURING FIRMS IN PORT HARCOURT, NIGERIA

\begin{tabular}{|c|c|c|c|}
\hline \hline Job & Due Date & $\begin{array}{c}\text { Processing } \\
\text { time in days }\end{array}$ & $\begin{array}{c}\text { Slack time } \\
\text { (Due date - processing time) }\end{array}$ \\
\hline A & 12 & 10 & $12-10=2$ \\
\hline B & 14 & 6 & $14-6=8$ \\
\hline C & 8 & 8 & $8-8=0$ (i.e. no slack time and very critical) \\
\hline D & 18 & 14 & $18-14=4$ \\
\hline E & 10 & 4 & $10-4=6$ \\
\hline
\end{tabular}

It is important to note that jobs with minimum time (i.e. critical job) were done first by the minimum slack time rule as argued by Clarke (1989), the jobs in the firms were assigned in the following order: C, A, D, E, B.

The flow time was therefore calculated as follows:

\begin{tabular}{|l|c|c|c|c|c|}
\hline Job & C & A & D & E & B \\
\hline Job time in days & 8 & 10 & 14 & 4 & 6 \\
\hline Cumulative time in days & 0 & 8 & 18 & 3236 & 42 \\
\hline
\end{tabular}

In related perspective, the mean flow time and mean lateness were calculated thus:

\begin{tabular}{|c|c|c|c|}
\hline Job & $\begin{array}{c}\text { Flow time } \\
\text { (i.e. cumulative) }\end{array}$ & $\begin{array}{c}\text { Time until } \\
\text { due date }\end{array}$ & $\begin{array}{c}\text { Lateness } \\
\text { (flow time - time available) }\end{array}$ \\
\hline A & 18 & 12 & 6 \\
\hline B & 42 & 14 & 28 \\
\hline C & 8 & 4 & 0 \\
\hline D & 32 & 18 & 14 \\
\hline E & 36 & 10 & $\mathbf{7 4}$ \\
\hline & $\mathbf{1 3 6}$ & & \\
\hline
\end{tabular}

Mean flow time $=\frac{136}{5}=27.2$ days

Mean lateness $=\frac{74}{5}=14.8$ days

c. The critical ratio according to Clarke (1989) is defined as:

Time remaining until due date

Work remaining 


\begin{tabular}{|c|c|c|c|}
\hline \hline Job & Time remaining until due date & Work remaining & Critical ratio \\
\hline A & 12 & 10 & $\frac{12}{10}=1.20$ \\
\hline B & 14 & 6 & $\frac{14}{6}=2.33$ \\
\hline C & 8 & 8 & $\frac{8}{8}=1.00$ \\
\hline D & 18 & 14 & $\frac{18}{14}=1.29$ \\
\hline E & 10 & 4 & $\frac{10}{4}=2.50$ \\
\hline
\end{tabular}

By using critical ratio methodology, the jobs were assigned in the following order; $C, A$, D, B, E. As a result, the flow times were therefore calculated thus:

\begin{tabular}{|l|c|c|c|c|c|}
\hline Job & C & A & D & B & E \\
\hline Time in days & 8 & 10 & 14 & 6 & 4 \\
\hline Cumulative time in days 0 & 08 & & 18 & 3238 & 42 \\
\hline
\end{tabular}

In that sequence, the mean flow time and mean lateness were calculated as follows:

\begin{tabular}{|c|c|c|c|}
\hline Job & $\begin{array}{c}\text { Flow } \\
\text { time }\end{array}$ & $\begin{array}{c}\text { Time until } \\
\text { due date }\end{array}$ & $\begin{array}{c}\text { Lateness } \\
\text { (flow time - Time available) }\end{array}$ \\
\hline A & 18 & 12 & $6(18-12)$ \\
\hline B & 38 & 14 & $24(38-14)$ \\
\hline C & 8 & 8 & $0(8-8)$ \\
\hline$D$ & 32 & 18 & $14(32-18)$ \\
\hline E & 42 & 10 & $32(42-10)$ \\
\hline & $\mathbf{1 3 8}$ & & $\mathbf{7 6}$ \\
\hline
\end{tabular}

Mean flow time $=\frac{138}{5}=27.6$ days

Mean lateness $=\frac{76}{5}=15.2$ days

d. The sequence E, B, C, A, D as seen above, gives the minimum flow time and minimum lateness. The shortest processing time rule as expressed by Clarke (1989) always results in minimum flow time and minimum lateness.

\section{Case 2: The sequence of two or more jobs through two machines}

The complete description of this sequences challenge or problem is as stated thus:

1) Only two machines are involved, i.e. A and B.

2) Each job is processed in the order, A, B. 
3) The exact or expected time $A_{1}, A_{2} \ldots \ldots . . A_{n}$;

$\mathrm{B}_{1}, \mathrm{~B}_{2} \ldots \ldots \ldots . \mathrm{B}_{\mathrm{n}}$ are known.

The problem is to minimize, $T$, the elapsed time from the start of the first job to the completion of the last job. It can be shown that the sequences that minimize $\mathrm{T}$ are the same for both machines. The method of computation, given here without proof is as expressed by Johnson (1954), and the method is as follows:

1) Select the smallest processing time occurring in the list.
$\mathrm{A}_{1}, \mathrm{~A}_{2}$, $\mathrm{An}_{\mathrm{n}}$
$\mathrm{B}_{1}, \mathrm{~B}_{2}$, ------ $\mathrm{B}_{\mathrm{n}}$.

Note: if there is a tie, one should select the smallest processing time.

2) If the minimum processing time is Ar, do the rth job first. If it is Bs, do the sth job last. It is important to note that this decision will apply to both machines A and B.

3) There are now n-r jobs left to be ordered. Apply steps 1 and 2 to the reduced set of processing time obtained by deleting the two machines processing times corresponding to the job already assigned.

4) Continue in this manner until all jobs have been ordered.

The resulting ordering will minimize $\mathrm{T}$.

For example, the following jobs as relatedly argued by Clarke (1989) must be processed on two machines, 1 and 2 in sequence, that is, each job should be first processed on machine 1 and then on 2.

\begin{tabular}{|c|c|c|}
\hline Job & $\begin{array}{c}\text { Processing time } \\
\text { on machine 1 in days }\end{array}$ & $\begin{array}{c}\text { Processing time } \\
\text { on machine 2 in days }\end{array}$ \\
\hline A & 8 & 6 \\
\hline B & 40 & 9 \\
\hline C & 15 & 0 \\
\hline D & 7 & 9 \\
\hline E & 3 & 7 \\
\hline F & 12 & 5 \\
\hline
\end{tabular}

Job $C$ is an exceptional because it has to be processed on machine 1 . The due date for all six jobs is 49 days from now. In view of this, one is expected to determine the order in which jobs should be sequenced,

1) using Johnson's rule;

2) using least slack per remaining operation rule, and

3) using critical ratio;

4) which method could be used and why?

\subsection{Solution}

a. Using Johnson's method, we selected the jobs in order of shortest processing time and assigned them as follows: 
PRODUCTION PLANNING AND CONTROL COMPLEMENTARITY ARCHITECTURE

IN SELECTED MANUFACTURING FIRMS IN PORT HARCOURT, NIGERIA

\begin{tabular}{|c|c|c|}
\hline \hline Order of selection & Job & Position in sequence \\
\hline $1^{\text {st }}$ & C & $6^{\text {th }}$ \\
\hline $2^{\text {nd }}$ & E & $1^{\text {st }}$ \\
\hline $3^{\text {rd }}$ & B & $2^{\text {nd }}$ \\
\hline $4^{\text {th }}$ & F & $5^{\text {th }}$ \\
\hline $5^{\text {th }}$ & A & $4^{\text {th }}$ \\
\hline $6^{\text {th }}$ & D & $3^{\text {rd }}$ \\
\hline
\end{tabular}

The jobs were assigned as follows: E, B, D, A, F, C.

The flow times for the jobs are as shown below:

Cumulative for machine 1

\begin{tabular}{|c|c|c|}
\hline Job & Processing time & Cumulative \\
\hline E & 6 & 6 \\
\hline B & 8 & 14 \\
\hline D & 14 & 28 \\
\hline A & 16 & 44 \\
\hline F & 24 & 68 \\
\hline C & 30 & 98 \\
\hline
\end{tabular}

Cumulative for machine 2

\begin{tabular}{|c|c|c|}
\hline Job & Processing time & Cumulative \\
\hline E & 14 & 14 \\
\hline B & 18 & 32 \\
\hline D & 18 & 50 \\
\hline A & 12 & 62 \\
\hline F & 10 & 72 \\
\hline
\end{tabular}

\section{Conclusions}

Significant attempts have been made to explicitly discuss the two constructs of production planning and control of production operations. Production planning and control should be tailored explicitly to strategically support the various strategies that will help the business to responsibly cut down costs for the purpose of achieving superior performance. Production planning and control divisions, types and functions, embody the techniques and mechanisms which company should employ to pursue strategies, in order to accomplish organizational goals and objectives. Scheduling and sequencing of operations have been revealed as a panacea that help the handling of time, space constraints and associated cost elements in operational management.

\subsection{Recommendations}

The study recommends that, production and control operations functions and patterns should complement each other in operational management. In addition, they should also be jealously guided in strategic management architecture in order to achieve firms' objectives and sustainability. 


\section{Conflict of Interest}

The author(s) declares that there is no conflict of interest.

\section{About the Authors}

Biriowu, C. S. (PhD) the Author of "Production Planning and Control Complementarity Architecture In Selected Manufacturing Firms In Port Harcourt, Nigeria"; obtained PhD in Management (Industrial Relations) from the prestigious Rivers State University, Port Harcourt; he is currently a senior lecturer in the aforementioned university in the Department of Management and specializing in the following courses: Management, Human Resources Management, Industrial Relations, Industrial Psychology. The author has written and published over (30) articles in both international and local journals which includes: The International Journal of Research in Business Management-IMPACT: IJRBM (Perspectives on the Determination of National Labour and Industrial Relations Policies: An Exploration of the Nigerian Experience). The American Journal of Management and Economics Innovations (The Nature of Firm's Internal Environment Capabilities and Competencies Dynamics Evaluation: Feasible Strategy Crafting Imperatives) and many more. Biriowu Chris has vast industry and academic experiences contributing towards the development of the economy and society at large; he has previously worked with Schlumberger Nigeria as the HR Compliance Manager and Industrial Relations Advisor for Sub Sahara Africa. Monier Construction Company, Nig. (Subsidiary of Ing Trap of Germany). Federal Ministry of Labour and Productivity, Lagos/Port Harcourt, Nig; etc., and has over 30 years of experience in the industry. He is currently working on other articles yet to be published.

John E. Chikwe (PhD) co-author of "Production Planning and Control Complementarity Architecture In Selected Manufacturing Firms In Port Harcourt, Nigeria; is a senior lecturer in the Department of Management, University of Port Harcourt, Port Harcourt, Rivers State.

\section{References}

Chikwe, J. E. \& Biriowu, S. C. (2018). Strategic Planning and Firm's Sustainability in Turbulent Business Operating Environment: Lessons from Oil and Gas Industry in Nigeria. International Journal of Business and General Management, 7(6), 5-16, Tamil Nadu, India, Oct-Nov.

Chikwe, J. E. \& Omojefe, G. O. (2017). Investment Decisions Criteria and Modeling Strategic: Investors Guide to Feasible Profitability and Management. Federal University Otuoke Journal of Business and Finance, 7(1), 128-136, March.

Chikwe, J. E. (n.d.). Business Policy and Strategic Management Dynamics, Text and Cases, (In Press) 
Clarke, G. (1989). Production and Operations Management. An Unpublished MBA Management Lecture Monograph, Department of Management, University of Port Harcourt.

Jain, R. K. \& Rao, S. S. (2009). Industrial Safety, Health and Environment Management Systems, New Delhi: Khanna Publishers.

Johnson, S. M. (1954). Sequencing of Operations, Naval Research Quarterly, (1), March.

Urieto, J. E. Umoh, G. I. \& Chikwe, J. E. (2011). Production and Operations Management, Port Harcourt: Divine Project Publishers. 

distribute, transmit or adapt the article content, providing a proper, prominent and unambiguous attribution to the authors in a manner that makes clear that the materials are being reused under permission of a Creative Commons License. Views, opinions and conclusions expressed in this research article are views, opinions and conclusions of the author(s). Open Access Publishing Group and European Journal of Management and Marketing Studies shall not be responsible or answerable for any loss, damage or liability caused in relation to/arising out of conflict of interests, copyright violations and inappropriate or inaccurate use of any kind content related or integrated on the research work. All the published works are meeting the Open Access Publishing requirements and can be freely accessed, shared, modified, distributed and used in educational, commercial and non-commercial purposes under a Creative Commons Attribution 4.0 International License (CC BY 4.0). 